\title{
Identification and characterization of Burkholderia multivorans CCA53
}

\author{
Hironaga Akita ${ }^{1 *}$, Zen-ichiro Kimura ${ }^{2}$, Mohd Zulkhairi Mohd Yusoff ${ }^{1,3}$, Nobutaka Nakashima $^{4,5}$ \\ and Tamotsu Hoshino ${ }^{1,4}$
}

\begin{abstract}
Objective: A lignin-degrading bacterium, Burkholderia sp. CCA53, was previously isolated from leaf soil. The purpose of this study was to determine phenotypic and biochemical features of Burkholderia sp. CCA53.

Results: Multilocus sequence typing (MLST) analysis based on fragments of the $a \operatorname{tpD}$, gltD, gyrB, lepA, rec $A$ and $\operatorname{trp} B$ gene sequences was performed to identify Burkholderia sp. CCA53. The MLST analysis revealed that Burkholderia sp. CCA53 was tightly clustered with B. multivorans ATCC BAA- $247^{\top}$. The quinone and cellular fatty acid profiles, carbon source utilization, growth temperature and $\mathrm{pH}$ were consistent with the characteristics of B. multivorans species. Burkholderia sp. CCA53 was therefore identified as B. multivorans CCA53.
\end{abstract}

Keywords: Burkholderia multivorans, MLST analysis, Lignin-degrading bacterium, Second-generation biofuel

\section{Introduction}

The genus Burkholderia was firstly proposed by Yabuuchi et al. [1], and was classified as Gram-negative and nonspore forming $\beta$-proteobacteria. To date, more than 80 Burkholderia species have been reported, and two major clusters and several subgroups have been proposed based on phylogenetic analyses of the $16 \mathrm{~S}$ rRNA, acd, gyrB, rec $A$ and $r p o B$ gene sequences, as well as their genome sequences [2]. Group A contains plant-associated and saprophytic species [2]. For example, nitrogen fixation in legumes is facilitated by $B$. mimosarum, $B$. nodosa, $B$. sabiae, B. tuberum and B. phymatum [3]. Also, growth rates of a few plants are promoted by $B$. phytofirmans and B. unamae [3]. On the other hand, group B contains opportunistic pathogens that infect animals, humans and plants [2]. B. cenocepacia, B. latens and B. multivorans infect to cystic fibrosis patients, which leads to pneumonic illness $[4,5]$. B. cenocepacia, B. multivorans and $B$. vietnamiensis show infectivity to alfalfa and lettuce [6].

\footnotetext{
*Correspondence: h-akita@aist.go.jp

${ }^{1}$ Research Institute for Sustainable Chemistry, National Institute of Advanced Industrial Science and Technology (AIST), 3-11-32 Kagamiyama, Higashi-Hiroshima, Hiroshima 739-0046, Japan

Full list of author information is available at the end of the article
}

Several Burkholderia species are now being utilized in industrial applications as biocatalysts $[7,8]$, for biodegradation [9] and as plant growth-promoting rhizobacteria [3]. For example, B. fungorum DBT1 is capable of assimilating polycyclic aromatic hydrocarbons, which is useful for bioremediation of contaminated soils [10]. B. cepacia GS3C exhibits highly efficient degradation during bioremediation of oil-contaminated soil $[11,12]$, and $B$. cepacia PCL3 is useful for treating carbofuran-contaminated water [13]. In addition, several antibiotics, including cepaciamide A [14], glidobactin A [15], pyrrolnitrin [16] and xylocandins [17] are produced by Burkholderia species. Several Burkholderia species showed lignin degradation capabilities [18], which are favorable to produce second-generation biofuels from lignocellulosic biomass. Thus, Burkholderia species are versatile bacteria with potential applicability in the biochemical and pharmaceutical industries. We previously isolated Burkholderia sp. CCA53 from leaf soil [19] and determined the draft genome sequence of the strain [20]. In this study, we report the phenotypic and biochemical characterization of Burkholderia sp. CCA53. 


\section{Main text Methods}

MLST analysis was performed according to the method of Urwin and Maiden [21]. A phylogenetic tree of concatenated sequences (9348 bp), including fragments of six housekeeping genes [atpD (1380 bp), gltD (1467 bp), gyrB (2469 bp), lepA (1794 bp), recA (1044 bp), $\operatorname{trp} B$ (1194 bp)] from Burkholderia sp. CCA53, was reconstructed based on the neighbor-joining method [22]. The calculation of distances, multiple alignment and construction of neighbor-joining phylogenetic trees were performed using CLUSTAL W version 1.83 [23]. All gene sequences are available in the GenBank/EMBL/DDBJ databases under the accession numbers BDDJ01000001 to BDDJ01000004.

Burkholderia sp. CCA53 (strain number: HUT-8135) was cultured in Nutrient Broth (Kyokuto, Tokyo, Japan). The $\mathrm{OD}_{600}$ was monitored by measuring the difference between the cell and cell-free culture turbidity values using an Eppendorf BioSpectrometer (Eppendorf, Hamburg, Germany). Carbon source utilization was determined using API 20E (bioMérieux, Marcy-l'Etoile, France) and API 50CHE (bioMérieux) according to the manufacturer's instructions. The effects of temperature $\left(10-60{ }^{\circ} \mathrm{C}\right)$ and $\mathrm{pH}(3.0-10.0)$ on the growth were studied.

The lipid was extracted from lyophilized cells according to the method of Bligh and Dyer [24], and then loaded onto a Sep-Pak Plus Silica cartridge (Waters, Milford, MA, USA). After washing the cartridge, the quinone was eluted. Quinone quantification was performed using an ACQUITY UPLC system (Waters) with an Eclipse Plus C18 column (Agilent technologies, Santa Clara, CA, USA). The chromatographic conditions were as follows: mobile phase, methanol/isopropanol $(3: 1 \mathrm{v} / \mathrm{v})$; flow rate, $0.5 \mathrm{~mL} \mathrm{~min}^{-1}$; the column oven temperature, $35^{\circ} \mathrm{C}$. The identification of quinone forms was carried out as previously described [25].

The cellular fatty acid compositions were determined using the Sherlock Microbial Identification System Version 6.0 (MIDI, Newark, DE, USA) and TSBA6 database (MIDI).

\section{Results}

Using MLST analysis with housekeeping genes, several Burkholderia species were identified. For example, the existence of Burkholderia cepacia complex species in moso bamboo plantations [26] and water bodies [6] were determined by MLST analysis based on fragments of the $\operatorname{atpD}, \operatorname{glt} B D, \operatorname{gyr} B, \operatorname{lep} A, \operatorname{rec} A$, phaC and $\operatorname{trp} B$ gene sequences. Moreover, Burkholderia phylogeny was revealed by rMLST, which was constructed based on the ribosomal protein-encoding genes of Burkholderia species [27]. To identify the phylogeny of Burkholderia sp. CCA53, we also performed an MLST analysis based on fragments of the $a t p D, g l t D, g y r B, \operatorname{lep} A, \operatorname{rec} A$ and $\operatorname{trp} B$ gene sequences (Fig. 1). The form of the resultant phylogenetic tree was similar to those of MLST $[6,26]$. The MLST analysis showed that Burkholderia sp. CCA53 shared a high degree of similarity with B. pseudomultivorans MSMB060 (95.7\%) and B.ubonensis MSMB22 (94.0\%). Moreover, Burkholderia sp. CCA53 was closely related to B. multivorans ATCC BAA- $247^{\mathrm{T}}$ (99.6\%), ATCC 17616 (98.7\%) and DDS 15A-1 (98.7\%). Thus, Burkholderia sp. CCA53 was identified as B. multivorans CCA53.

When B. multivorans CCA53 was cultured aerobically in Nutrient Broth, ubiquinone- 8 was detected as the major respiratory quinone $(98.7 \%)$, and a small amount of ubiquinone- 9 was also detected (1.3\%). This suggests that ubiquinone- 8 exclusively functions in the quinone system of B. multivorans CCA53, which is consistent with the quinone profiles of B. kururiensis [29], B. megalochromosomata [30] and B. uboniae [31].

The following fatty acids were present in $B$. multivorans CCA53: $\mathrm{C}_{12: 0}(0.1 \%), \mathrm{C}_{13: 1}(0.7 \%), \mathrm{C}_{14: 0}(4.2 \%), \mathrm{C}_{14: 0} 2-\mathrm{OH}$ (0.2\%), $\mathrm{C}_{16: 0}$ (24.0\%), $\mathrm{C}_{16: 0} 2-\mathrm{OH}$ (1.8\%), $\mathrm{C}_{16: 0} 3-\mathrm{OH}$ (6.0\%), $\mathrm{C}_{16: 1} 2-\mathrm{OH}(1.3 \%), \mathrm{C}_{17: 0}(0.4 \%)$, anteiso- $\mathrm{C}_{17: 0} \omega 9 \mathrm{c}$ (0.1\%), cyclo- $\mathrm{C}_{17: 0}(8.4 \%), \mathrm{C}_{18: 0}(1.5 \%), \mathrm{C}_{18: 1} \omega 5 \mathrm{c}(0.1 \%)$, $11-$ methyl- $\mathrm{C}_{18: 1} \omega 7 \mathrm{c}(0.1 \%)$, cyclo- $\mathrm{C}_{19: 0} \omega 8 \mathrm{c}(9.0 \%)$, iso$\mathrm{C}_{19: 0}(0.2 \%)$, summed feature 2 (comprising $\mathrm{C}_{14: 0} 3-\mathrm{OH}$, and/or iso- $C_{16: 1} \mathrm{I}$, and/or $\mathrm{C}_{12: 0}$ unidentified aldehyde or an unidentified fatty acid with equivalent chain length of 10.928) (5.8\%), summed feature 3 (comprising $C_{16: 1} \omega 6 c$ and/or $\left.C_{16: 1} \omega 7 \mathrm{c}\right)(11.6 \%)$ and summed feature 8 (comprising $C_{18: 1} \omega 6 \mathrm{c}$ and/or $\left.C_{18: 1} \omega 7 \mathrm{c}\right)(24.6 \%)$. The unsaturated fatty acids $C_{16: 1} \omega 6 c, C_{16: 1} \omega 7 c, C_{18: 1} \omega 6 c$ and $C_{18: 1}$ $\omega 7 \mathrm{c}$ were major components of $B$. multivorans CCA53. This fatty acid profile conformed to the profiles of $B$. multivorans ATCC 17616 [32] and B. multivorans CGD2 [32].

To determine its carbon source utilization, B. multivorans CCA53 was cultured with each carbon sources. This revealed that $B$. multivorans CCA53 utilized the following compounds as carbon sources for growth: amygdalin, D-lactose, D-maltose, D-cellobiose, D-arabinose, L-arabinose, D-fucose, D-fructose, D-galactose, D-glucose, D-mannose, D-ribose, D-xylose, D-adonitol, D-arabitol, L-arabitol, dulcitol, inositol, D-mannitol, D-sorbitol, L-arginine, L-lysine, L-ornithine, L-tryptophane, citrate, pyruvate and urea. Among those, assimilation of D-galactose, D-glucose, D-mannose, D-xylose, D-adonitol, inositol and D-sorbitol is common to Burkholderia species [1]. On the other hand, no growth occurred on gelatin, glycogen, starch, inulin, D-melezitose, D-raffinose, arbutin, esculin ferric citrate, gentiobiose, D-melibiose, 


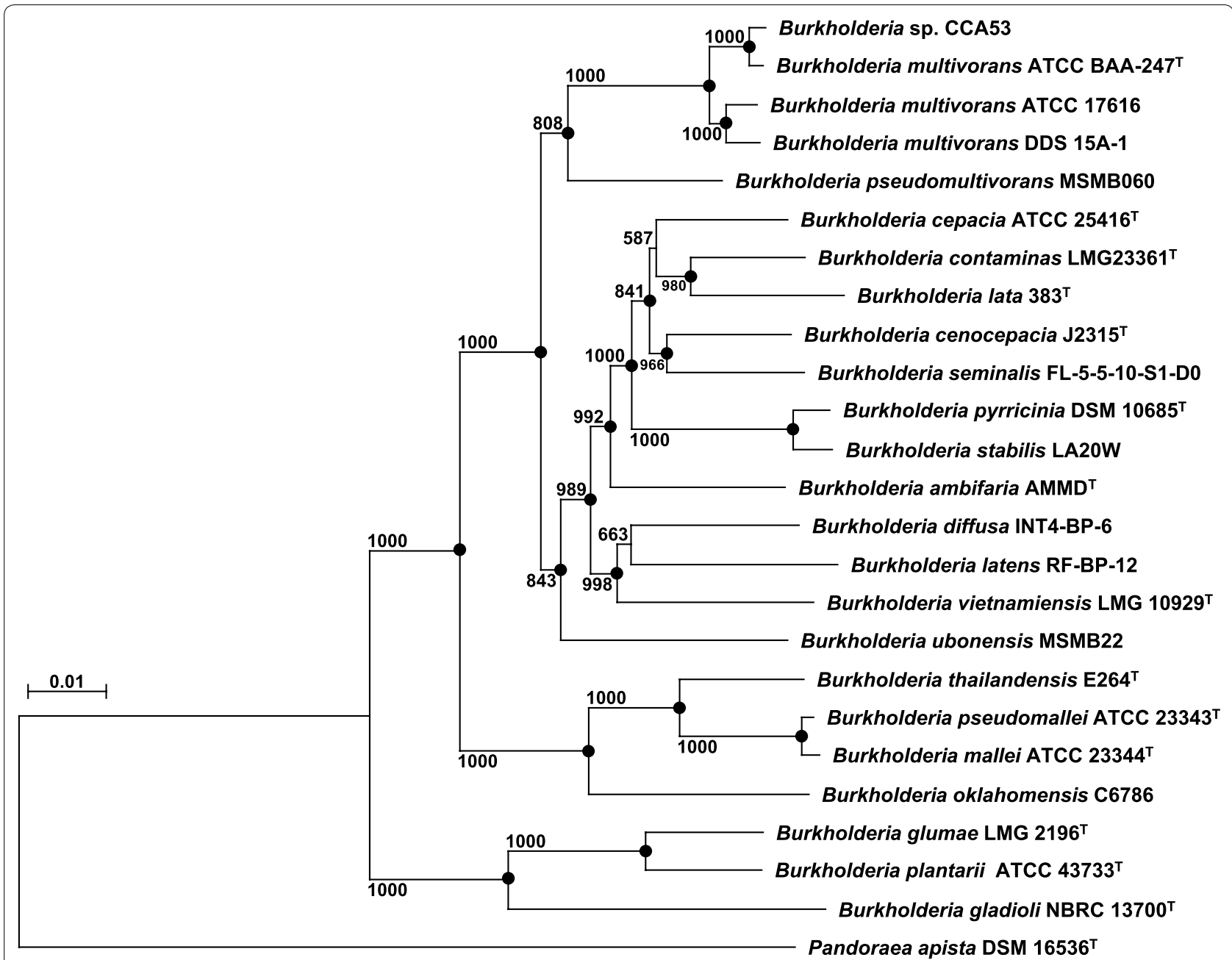

Fig. 1 Phylogenetic tree reconstructed from analysis of the sequences of six housekeeping genes ( $a t p D$, gltD, gyrB, lepA, rec $A$ and trpB) and $\operatorname{show}$ ing the relationship of CCA53 with related species. Pandoraea apista DSM $16536^{\top}$ was used as an outgroup. The tree was reconstructed using the neighbor-joining method with Kimura's two-parameter model [28]. Closed circles show the nodes supported by $80 \%$ bootstrap probabilities with 1000 replicates. The bar indicates the $1 \%$ nucleotide substitution rate

2-nitrophenyl $\beta$-D-galactopyranoside, salicin, D-sucrose, D-trehalose, D-turanose, $N$-acetyl-glucosamine, L-fucose, D-lyxose, methyl- $\alpha$-D-glucopyranoside, methyl- $\alpha-D-$ mannopyranoside, methyl- $\beta$-D-xylopyranoside, L-rhamnose, L-sorbose, D-tagatose, L-xylose, gluconate, 2-keto gluconate, 5-keto gluconate, D-mannito, xylitol, erythritol, glycerol or thiosulfate.

When B. multivorans CCA53 was cultured in Nutrient Broth at various temperatures $\left(10-60{ }^{\circ} \mathrm{C}\right)$, the maximum growth rate was achieved at $20{ }^{\circ} \mathrm{C}$ (Fig. 2a). The strain was capable of growing at temperatures between 20 and $50{ }^{\circ} \mathrm{C}$, but no growth was seen at $60^{\circ} \mathrm{C}$ (Fig. 2a). At $30{ }^{\circ} \mathrm{C}$, the maximum growth rate of $\mathrm{B}$. multivorans CCA53 was at $\mathrm{pH} 4.0$ (Fig. 2b). Moreover, the strain grew effectively at pHs between 4.0 and 9.0, but growth rates were sharply lower at pHs below 3.0 or above 10.0 (Fig. 2b). These characteristics were nearly the same as those of $B$. multivorans NKI379, which was also isolated from soil samples in the Er-Ren River Basin, Taiwan [33].

\section{Discussion}

From the viewpoints of economics, ecology and environmental protection, it would be advantageous to produce biofuels from lignocellulosic biomass, which are known as second-generation biofuels [34]. When second-generation biofuels are produced from lignocellulosic biomass, consecutive pretreatment, enzymatic hydrolysis and microbial fermentation steps are required. During the pretreatment step, lignocellulosic biomass is decomposed through heating, which releases cellulose, hemicellulose 

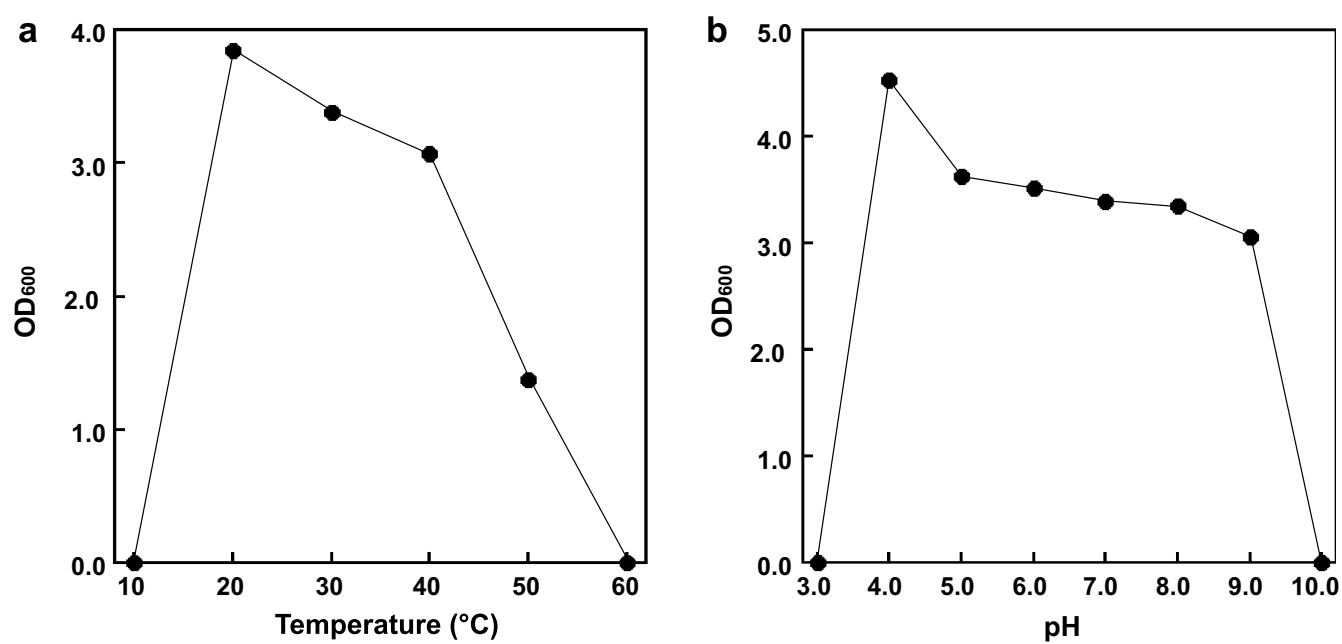

Fig. 2 Effects of temperature and pH on growth of B. multivorans CCA53. Cells were cultured in Nutrient Broth. Error bars indicate SE $(n=3)$

and lignin. At the enzymatic hydrolysis step, cellulose and hemicellulose are converted into saccharified solution, which includes fermentable sugars, aldehyde inhibitors and lignin. In the fermentation step, the fermentable sugars are used as carbon sources by engineered Escherichia coli, Saccharomyces cerevisiae or other microorganisms [35, 36]. Although aldehyde inhibitors inhibit microbial growth and interfere with subsequent fermentation, these compounds can be chemically or enzymatically detoxified [34, 37]. However lignin is not effectively utilized by the aforementioned microorganisms, causing the yield to be low $[35,36]$. Microbial degradation of lignin has been primarily studied in brown- and white-rot fungi. Using the Fenton reaction, brown-rot fungi produce free hydroxyl radicals from hydrogen peroxide, after which the free hydroxyl radicals are used in the lignin degradation [38]. Moreover, white-rot fungi are capable of producing several extracellular ligninolytic enzymes, including laccase, lignin peroxidase, manganese peroxidase and versatile peroxidase, which are also useful for lignin degradation [39]. On the other hand, these fungi show slower growth rates and require for long incubation times, which elevates the production costs and draws lower productivities. A few bacterial species belonging to the genera Arthrobacter, Burkholderia, Comamonas, Pseudomonas, Sphingobium, Streptomyces and Rhodococcus show faster growth rates and lignin degradation capabilities, but their capabilities are lower than those of fungi [18]. We therefore screened for lignin-degrading bacteria with rapid growth rates and high capabilities for lignin degradation, and a candidate bacterium was isolated from leaf soil [19]. Based on its 16S rRNA gene sequence homology, the bacterium was identified as
Burkholderia sp. CCA53 [19]. This strain was capable of utilizing lignin as a sole carbon source, and it was anticipated that Burkholderia sp. CCA53 would have industrial potential for second-generation biofuel production [19]. In the present study, therefore, we characterized the phenotypic and biochemical features of Burkholderia sp. CCA53. Several Burkholderia species, including B. cepacia KK01 [40] and Burkholderia sp. LIG30 [41] also have a capacity to degrade lignin. In Burkholderia sp. LIG30, the mechanism of its lignin degradation is suggested by its expression of two genes predicted to encode multicopper oxidase and 22 genes encoding putative catalases or peroxidases [41]. Within the draft genome sequence of $B$. multivorans CCA53, one gene predicted to encode multi-copper oxidase and 21 genes encoding putative catalases or peroxidases were also confirmed [20]. This suggests the mechanism for lignin degradation used by $B$. multivorans CCA53 may be similar to that used by Burkholderia sp. LIG30.

When saccharified solutions are prepared from sugarcane, cassava and their wastes, D-glucose and L-xylose are the main saccharides $[42,43]$, though small amounts of D-lactose and D-maltose are also present $[42,43]$. Several Burkholderia species cannot assimilate D-lactose or D-maltose [29], but B. multivorans CCA53 was able to use all of these disaccharides as carbon sources, which means that B. multivorans CCA53 could be a useful strain for production of second-generation biofuels [35, 36]. Moreover, we think that B. multivorans CCA53 may have other advantages for industrial application beyond utilization of lignin. The first is that B. multivorans CCA53 showed efficient growth at acidic pH (Fig. 2b). Several lignocellulosic biomass-degrading enzymes 
showed maximum activities at acidic $\mathrm{pH}$ [44-46], which means that the saccharified solution $\mathrm{pH}$ is also acidic. By contrast, the growth of industrial bacteria such as $E$. coli is inefficient at acidic $\mathrm{pH}$. Consequently, $\mathrm{pH}$ control is required at the fermentation step with engineered $E$. coli, whereas B. multivorans CCA53 would not require $\mathrm{pH}$ control. Second, the optimal growth $\mathrm{pH}$ for $B$. multivorans CCA53 would be expected to prevent contamination by microorganisms in larger scale fermentations. Third, B. multivorans CCA53 showed strong growth at $20-40{ }^{\circ} \mathrm{C}$ (Fig. 2a), which is similar to the mesophilic conditions required for E. coli and S. cerevisiae. This means that the existing systems for biofuel fermentation will be applicable for use with B. multivorans CCA53.

\section{Limitations}

In this paper, we reported the phylogenetic, phenotypic and biochemical characterization of Burkholderia sp. CCA53. To identify the phylogeny of Burkholderia sp. CCA53, we performed MLST analysis. In addition, results of phenotypic and biochemical analyses were consistent with the characteristics of $B$. multivorans species. Burkholderia sp. CCA53 was therefore identified as $B$. multivorans CCA53. These results may give little interest for microbiologists.

\section{Abbreviation}

MLST: multilocus sequence typing.

\section{Authors' contributions}

HA designed this study, performed experiments, participated in the interpretation of the results and drafted the manuscript. ZK and MZMY participated in the design and coordination of this study and helped to revise the manuscript. NN and TH conceived and designed this study, coordinated the experiments, interpreted the results and revised the manuscript for important intellectual content. All authors read and approved the final manuscript.

\section{Author details \\ 1 Research Institute for Sustainable Chemistry, National Institute of Advanced Industrial Science and Technology (AIST), 3-11-32 Kagamiyama, Higashi-Hiro- shima, Hiroshima 739-0046, Japan. ${ }^{2}$ Department of Civil and Environ- mental Engineering, National Institute of Technology, Kure College, 2-2-11 Aga-minami, Kure, Hiroshima 737-8506, Japan. ${ }^{3}$ Department of Bioprocess Technology, Faculty of Biotechnology and Biomolecular Sciences, Universiti Putra Malaysia, 43400 Serdang, Selangor, Malaysia. ${ }^{4}$ Bioproduction Research Institute, National Institute of Advanced Industrial Science and Technology (AIST), 2-17-2-1 Tsukisamu-Higashi, Toyohira-ku, Sapporo, Hokkaido 062-8517, Japan. ${ }^{5}$ Department of Biological Information, Graduate School of Bioscience and Biotechnology, Tokyo Institute of Technology, 2-12-1-M6-5 Ookayama, Meguro-ku, Tokyo 152-8550, Japan.}

\section{Acknowledgements}

We are grateful to all members of the Bio-conversion Research Group at our Institute [Research Institute for Sustainable Chemistry, National Institute of Advanced Industrial Sciences and Technology (AIST)] for their technical assistance and valuable discussion.

\section{Competing interests}

The authors declare that they have no competing interests.

\section{Availability of data and materials}

The nucleotide sequence and annotation data for the B. multivorans CCA53 draft genome have been deposited in DDBJ/EMBL/GeneBank under Accession Numbers BDDJ01000001 to BDDJ01000004.

\section{Funding}

This work was supported in part by the Science and Technology Research Partnership for Sustainable Development (SATREPS), under Japan Science and Technology Agency (JST) and Japan International Cooperation Agency (JICA).

\section{Publisher's Note}

Springer Nature remains neutral with regard to jurisdictional claims in published maps and institutional affiliations.

Received: 14 June 2016 Accepted: 26 June 2017

Published online: 06 July 2017

\section{References}

1. Yabuuchi E, Kosako Y, Oyaizu H, Yano I, Hotta H, Hashimoto Y, Ezaki T, Arakawa M. Proposal of Burkholderia gen. nov. and transfer of seven species of the genus Pseudomonas homology group II to the new genus, with the type species Burkholderia cepacia (Palleroni and Holmes 1981) comb. nov. Microbiol Immunol. 1992;36:1251-75.

2. Estrada-de los SP, Vinuesa P, Martínez-Aguilar L, Hirsch AM, CaballeroMellado J. Phylogenetic analysis of Burkholderia species by multilocus sequence analysis. Curr Microbiol. 2013;67:51-60.

3. Suárez-Moreno ZR, Caballero-Mellado J, Coutinho BG, MendonçaPreviato L, James EK, Venturi V. Common features of environmental and potentially beneficial plant-associated Burkholderia. Microb Ecol. 2012;63:249-66.

4. Horsley A, Perry C, Martin K, Webb K, Turton J, Kenna D, Jones A. Burkholderia latens infection in cystic fibrosis. J Cyst Fibros. 2011;10:291-2.

5. Jones AM, Dodd ME, Govan JR, Barcus V, Doherty CJ, Morris J, Webb AK. Burkholderia cenocepacia and Burkholderia multivorans: influence on survival in cystic fibrosis. Thorax. 2004;59:948-51.

6. Ibrahim M, Tang Q, Shi Y, Almoneafy A, Fang Y, Xu L, Li W, Li B, Xie GL. Diversity of potential pathogenicity and biofilm formation among Burkholderia cepacia complex water, clinical, and agricultural isolates in China. World J Microbiol Biotechnol. 2012;28:2113-23.

7. Amin A, Chauhan S, Dare M, Bansal AK. Degradation of parabens by Pseudomonas beteli and Burkholderia latens. Eur J Pharm Biopharm. 2010:75:206-12.

8. Singh A, Basit A, Banerjee UC. Burkholderia cenocepacia: a new biocatalyst for efficient bioreduction of ezetimibe intermediate. J Ind Microbiol Biotechnol. 2009;36:1369-74.

9. Mohanty S, Mukherji S. Surfactant aided biodegradation of NAPLs by Burkholderia multivorans: comparison between Triton X-100 and rhamnolipid JBR-515. Colloids Surf B Biointerfaces. 2013;102:644-52.

10. Andreolli M, Lampis S, Zenaro E, Salkinoja-Salonen M, Vallini G. Burkholderia fungorum DBT1: a promising bacterial strain for bioremediation of PAHs-contaminated soils. FEMS Microbiol Lett. 2011;319:11-8.

11. Shen W, Zhu N, Cui J, Wang H, Dang Z, Wu P, Luo Y, Shi C. Ecotoxicity monitoring and bioindicator screening of oil-contaminated soil during bioremediation. Ecotoxicol Environ Saf. 2016;124:120-8.

12. Tang $X$, He LY, Tao XQ, Dang $Z$, Guo CL, Lu GN, Yi XY. Construction of an artificial microalgal-bacterial consortium that efficiently degrades crude oil. J Hazard Mater. 2010;181:1158-62.

13. Laocharoen S, Plangklang P, Reungsang A. Selection of support materials for immobilization of Burkholderia cepacia PCL3 in treatment of carbofuran-contaminated water. Environ Technol. 2013;34:2587-97.

14. Jiao Y, Yoshihara T, Ishikuri S, Uchino H, Ichihara A. Structural identification of cepaciamide A, a novel fungitoxic compound from Pseudomonas cepacia D-202. Tetrahedron Lett. 1996;37:1039-42.

15. Schellenberg B, Bigler $L$, Dudler R. Identification of genes involved in the biosynthesis of the cytotoxic compound glidobactin from a soil bacterium. Environ Microbiol. 2007;9:1640-50. 
16. El-Banna N, Winkelmann G. Pyrrolnitrin from Burkholderia cepacia: antibiotic activity against fungi and novel activities against streptomycetes. J Appl Microbiol. 1998;85:69-78.

17. Meyers E, Bisacchi GS, Dean L, Liu WC, Minassian B, Slusarchyk DS, Sykes RB, Tanaka SK, Trejo W. Xylocandin: a new complex of antifungal peptides. I. Taxonomy, isolation and biological activity. J Antibiot (Tokyo). 1987:40:1515-9.

18. Bugg TD, Ahmad M, Hardiman EM, Singh R. The emerging role for bacteria in lignin degradation and bio-product formation. Curr Opin Biotechnol. 2011;22:394-400.

19. Akita H, Kimura Z, Mohd Yusoff MZ, Nakashima N, Hoshino T. Isolation and characterization of Burkholderia sp. strain CCA53 exhibiting ligninolytic potential. Springerplus. 2016;5:596.

20. Akita H, Kimura Z, Mohd Yusoff MZ, Nakashima N, Hoshino T. Draft genome sequence of Burkholderia sp. strain CCA53, isolated from leaf soil. Genome Announc. 2016;4:e00630-716.

21. Urwin R, Maiden MC. Multi-locus sequence typing: a tool for global epidemiology. Trends Microbiol. 2003;11:479-87.

22. Saitou N, Nei M. The neighbor-joining method: a new method for reconstructing phylogenetic trees. Mol Biol Evol. 1987;4:406-25.

23. Thompson JD, Higgins DG, Gibson TJ. CLUSTAL W: improving the sensitivity of progressive multiple sequence alignment through sequence weighting, position-specific gap penalties and weight matrix choice. Nucleic Acids Res. 1994;22:4673-80.

24. Bligh EG, Dyer WJ. A rapid method of total lipid extraction and purification. Can J Biochem Physiol. 1959;37:911-7.

25. Tamaoka J, Katayama-Fujimura Y, Kuraishi H. Analysis of bacterial menaquinone mixtures by high performance liquid chromatography. J Appl Bacteriol. 1983;54:31-6.

26. Lou M, Fang Y, Zhang G, Xie G, Zhu B, Ibrahim M. Diversity of Burkholderia cepacia complex from the Moso bamboo (Phyllostachys edulis) rhizhosphere soil. Curr Microbiol. 2011;62:650-8.

27. Depoorter E, Bull MJ, Peeters C, Coenye T, Vandamme P, Mahenthiralingam E. Burkholderia: an update on taxonomy and biotechnological potential as antibiotic producers. Appl Microbiol Biotechnol. 2016;100:5215-29.

28. Kimura M. A simple method for estimating evolutionary rates of base substitutions through comparative studies of nucleotide sequences. J Mol Evol. 1980;16:111-20.

29. Zhang H, Hanada S, Shigematsu T, Shibuya K, Kamagata Y, Kanagawa T, Kurane R. Burkholderia kururiensis sp. nov., a trichloroethylene (TCE)degrading bacterium isolated from an aquifer polluted with TCE. Int J Syst Evol Microbiol. 2000;50:743-9.

30. Baek I, Seo B, Lee I, Lee K, Park SC, Yi H, Chun J. Burkholderia megalochromosomata sp. nov., isolated from grassland soil. Int J Syst Evol Microbiol. 2015;65:959-64.

31. Yabuuchi E, Kawamura Y, Ezaki T, Ikedo M, Dejsirilert S, Fujiwara N, Naka T, Kobayashi K. Burkholderia uboniae sp. nov., L-arabinose-assimilating but different from Burkholderia thailandensis and Burkholderia vietnamiensis. Microbiol Immunol. 2000;44:307-17.

32. Ruskoski SA, Bullard JW, Champlin FR. Cell envelope phospholipid composition of Burkholderia multivorans. Curr Microbiol. 2014;69:388-93.

33. Lin HH, Chen YS, Li YC, Tseng IL, Hsieh TH, Buu LM, Chen YL. Burkholderia multivorans acts as an antagonist against the growth of Burkholderia pseudomallei in soil. Microbiol Immunol. 2011;55:616-24.

34. Kamm B, Kamm M, Gruber PR, Kromus S. Biorefinery Systems-An Overview. In: Kamm B, Gruber PR, Kamm M, editors. Biorefineries-industrial processes and products: status quo and future directions. Deutschland: WILEY-VCH Verlag GmbH \& Co. KGaA; 2008. p. 1-40.

35. Ho DP, Ngo HH, Guo W. A mini review on renewable sources for biofuel. Bioresour Technol. 2014;169:742-9.

36. Islam ZU, Zhisheng Y, el Hassan B, Dongdong C, Hongxun Z. Microbial conversion of pyrolytic products to biofuels: a novel and sustainable approach toward second-generation biofuels. J Ind Microbiol Biotechnol. 2015;42:1557-79.

37. Jönsson LJ, Alriksson B, Nilvebrant NO. Bioconversion of lignocellulose: inhibitors and detoxification. Biotechnol Biofuels. 2013;6:16.

38. Arantes V, Jellison J, Goodell B. Peculiarities of brown-rot fungi and biochemical Fenton reaction with regard to their potential as a model for bioprocessing biomass. Appl Microbiol Biotechnol. 2012;94:323-38.

39. Dashtban M, Schraft H, Syed TA, Qin W. Fungal biodegradation and enzymatic modification of lignin. Int J Biochem Mol Biol. 2010;1:36-50.

40. Kato K, Kozaki S, Sakuranaga M. Degradation of lignin compounds by bacteria from termite guts. Biotechnol Lett. 1998;20:459-62.

41. Woo HL, Utturkar S, Klingeman D, Simmons BA, DeAngelis KM, Brown SD, Hazen TC. Draft genome sequence of the lignin-degrading Burkholderia sp. strain LIG30, isolated from wet tropical forest soil. Genome Announc. 2014;2:e00637-006714.

42. Awasthi P, Shrivastava S, Kharkwal AC, Varma A. Biofuel from agricultural waste: a review. Int J Curr Microbiol App Sci. 2015;4:470-7.

43. Johnson R, Padmaja G, Moorthy SN. Comparative production of glucose and high fructose syrup from cassava and sweet potato roots by direct conversion techniques. Innov Food Sci Emerg Technol. 2009;10:616-20.

44. Alrumman SA. Enzymatic saccharification and fermentation of cellulosic date palm wastes to glucose and lactic acid. Braz J Microbiol. 2016;47:110-9.

45. Sartori T, Tibolla H, Prigol E, Colla LM, Costa JA, Bertolin TE. Enzymatic saccharification of lignocellulosic residues by cellulases obtained from solid state fermentation using Trichoderma viride. Biomed Res Int. 2015;2015:342716.

46. Zhao L, Cao GL, Wang AJ, Ren HY, Xu CJ, Ren NQ. Enzymatic saccharification of cornstalk by onsite cellulases produced by Trichoderma viride for enhanced biohydrogen production. Glob Change Biol Bioenergy. 2013;5:591-8.

\section{Submit your next manuscript to BioMed Central and we will help you at every step:}

- We accept pre-submission inquiries

- Our selector tool helps you to find the most relevant journal

- We provide round the clock customer support

- Convenient online submission

- Thorough peer review

- Inclusion in PubMed and all major indexing services

- Maximum visibility for your research

Submit your manuscript at www.biomedcentral.com/submit 